\title{
Treatment of Asthma in the Elderly: Questionnaire Survey in Japan
}

\author{
Sahoko Chiba', Kimitake Tsuchiya ${ }^{1 *}$, Tomoyuki Ogata², Reina Imase ${ }^{2}$, Tamon Yagi ${ }^{2}$, \\ Yuka Mishima ${ }^{2}$, Torahiko Jinta ${ }^{3}$, Kazuhito Saito ${ }^{4}$, Reiko Taki ${ }^{5}$, Susumu Isogai ${ }^{6}$, Yasuto Jinn ${ }^{7}$, \\ Tsutomu Kawasaki, Ichiro Natsume9 ${ }^{9}$, Yoshihiro Miyashita ${ }^{10}$, Jun Takagiwa ${ }^{11}$, Nobuo Ishiwata12, \\ Tomoshige Chiaki ${ }^{13}$, Masato Kishi ${ }^{14}$, Yoshikazu Tsukada ${ }^{15}$, Motohisa Yamasaki ${ }^{16}$, Naohiko Inase ${ }^{1}$ \\ ${ }^{1}$ Department of Respiratory Medicine, Tokyo Medical and Dental University, Tokyo, Japan \\ ${ }^{2}$ JA Toride Medical Center, Ibaraki, Japan \\ ${ }^{3}$ St. Luke's International Hospital, Tokyo, Japan \\ ${ }^{4}$ Tsuchiura Kyoudou General Hospital, Ibaraki, Japan \\ ${ }_{5}^{5}$ Japanese Red Cross Musashino Hospital, Tokyo, Japan \\ ${ }^{6}$ Ome Municipal General Hospital, Tokyo, Japan \\ ${ }^{7}$ Hiratsuka Kyosai Hospital, Kanagawa, Japan \\ ${ }^{8}$ Yokohama City Minato Red Cross Hospital, Kanagawa, Japan \\ ${ }^{9}$ Yokosuka Kyosai Hospital, Kanagawa, Japan \\ ${ }^{10}$ Yamanashi Prefectural Central Hospital, Yamanashi, Japan \\ ${ }^{11}$ Tokyo Kyosai Hospital, Tokyo, Japan \\ ${ }^{12}$ Kudanzaka Hospital, Tokyo, Japan \\ ${ }^{13}$ Hokushin General Hospital, Nagano, Japan \\ ${ }^{14}$ Mishima General Hospital, Shizuoka, Japan \\ ${ }^{15}$ Soka Municipal Hospital, Saitama, Japan \\ ${ }^{16}$ Nitobe Memorial Nakano General Hospital, Tokyo, Japan \\ Email: ${ }^{\star}$ ktsuchiya2017@gmail.com
}

How to cite this paper: Chiba, S., Tsuchiya, K., Ogata, T., Imase, R., Yagi, T., Mishima, Y., Jinta, T., Saito, K., Taki, R., Isogai, S., Jinn, Y., Kawasaki, T., Natsume, I., Miyashita, Y., Takagiwa, J., Ishiwata, N., Chiaki, T., Kishi, M., Tsukada, Y., Yamasaki, M. and Inase, N. (2017) Treatment of Asthma in the Elderly: Questionnaire Survey in Japan. International Journal of Clinical Medicine, 8, 236-247.

https://doi.org/10.4236/ijcm.2017.84023

Received: March 19, 2017

Accepted: April 27, 2017

Published: April 30, 2017

\begin{abstract}
Introduction: The prevalence of asthma in the elderly has been increasing due to the aging of the global population. Appropriate treatment for asthma in the elderly is now a major issue, as the disease is often fatal and incurs high medical costs in the elderly population. There have been few recent reports on asthma treatment for the elderly in the real-world clinical settings. Objectives: This study was performed to assess how respiratory physicians manage asthma in elderly patients in clinical settings in Japan. Methods: Respiratory physicians in 16 Japanese hospitals responded to a questionnaire survey on asthma and COPD treatment between December 2014 and February 2015. The analysis was performed using data collected from medical records on 2041 asthma patients. Results: The mean patient age was 61.2 years, and $36.6 \%$ of the patients were men. In the breakdown by age, 1018 (49.9\%) of the patients were elderly ( $\geq 65$ years). Compared to the non-elderly, the elderly patients
\end{abstract}


Copyright $\odot 2016$ by authors and Scientific Research Publishing Inc. This work is licensed under the Creative Commons Attribution International License (CC BY 4.0).

http://creativecommons.org/licenses/by/4.0/ had a significantly lower BMI, greater smoking history in pack-years, and poorer pulmonary function. There were no significant differences between the elderly and non-elderly in the prescription rates of common medications such as inhaled corticosteroids, long-acting beta-agonists (LABA) administered via inhaler or transdermal patch, long-acting muscarinic antagonists, or leukotriene receptor antagonists. In contrast, mucoactive drugs (18.7\% vs. $12.3 \%, P$ $<0.01)$ and macrolides $(7.9 \%$ vs. $4.0 \%, P<0.01)$ were prescribed more frequently for the elderly than for the non-elderly. The proportion of patients receiving transdermal LABA was higher in the elderly than in the non-elderly ( $4.7 \%$ vs. $2.4 \%, P=0.02$ ). Conclusions: According to this survey, the prescription rates of mucoactive drugs, macrolides, and transdermal LABA were significantly higher in the elderly than in the non-elderly.

\section{Keywords}

Asthma, Elderly, Transdermal LABA, Aging

\section{Introduction}

The prevalence of asthma among older adults has been reported to range from $2.5 \%$ to $7.0 \%$ in Europe and the United states [1] [2] [3] and is predicted to continue increasing in the future as the global population ages [4]. Asthma in the elderly requires urgent attention in view of the higher mortality rates, higher costs for hospitalization and medication, and poorer quality of life elderly asthmatics endure compared to younger adults with the disease [5] [6].

Elderly patients with asthma are more likely to be under diagnosed and undertreated [7], partly because the pathophysiology of asthma in the elderly becomes more complex with age-related changes such as loss of lung function [8], alterations in immune function such as elevated basal levels of inflammation and reduced innate and adaptive responses [9], and increasing comorbidities [10]. Long-term cigarette smoking might modify the pathophysiology of asthma in the elderly. Tobacco smoking exposure and aging have been identified as risk factors for the development of asthma-chronic obstructive pulmonary disease (COPD) overlap syndrome (ACOS), a condition characterized by partly irreversible airflow limitation, neutrophilic airway inflammation, and airway remodeling [11].

Japan currently has the world's oldest population. The elderly (65 years or older) accounted for $26.6 \%$ of the Japanese population in 2015 and are forecasted to account for about $40 \%$ by 2050 [12]. Accordingly, the proportion of adult asthma patients aged 65 and over has increased from 36.7\% in 1996 to $41.7 \%$ in 2014 [13]. While the total mortality from asthma has gradually decreased, the elderly (65 years or older) account for a growing percentage of asthma deaths in Japan. As of 2013, almost $90 \%$ of the patients who died from asthma were elderly [14]. While the appropriate treatment to reduce asthma mortality in the elderly is crucially needed, the treatments for the elderly some- 
times diverge from the current guidelines because of conditions such as inspiratory flow limitation, poor inhaler technique, cognitive impairment, and comorbidities [15] [16]. Drug-drug interactions are another particular concern in the elderly, as well as adverse drug effects induced by dysfunctions of the liver and kidney [17]. Elderly patients have also been excluded from many of the clinical trials [4], which limits the available data on asthma treatment strategies for them.

In this study, we aimed to assess how respiratory physicians manage asthma in the elderly in real-world clinical settings in Japan.

\section{Materials and Methods}

\subsection{Study Design and Subjects}

This is a cross-sectional study based on data collected from a questionnaire survey filled out by respiratory physicians on the asthma and COPD treatment they administered in Tokyo Medical and Dental University and 15 affiliated hospitals (JA Toride Medical Center, St. Luke's International Hospital, Tsuchiura Kyoudou General Hospital, Japanese Red Cross Musashino Hospital, Ome Municipal General Hospital, Hiratsuka Kyosai Hospital, Yokohama City Minato Red Cross Hospital, Yokosuka Kyosai Hospital, Yamanashi Prefectural Central Hospital, Tokyo Kyosai Hospital, Kudanzaka Hospital, Hokushin General Hospital, Mishima General Hospital, Soka Municipal Hospital, Nitobe Memorial Nakano General Hospital) between December 2014 and February 2015. The inclusion criteria for the patients covered by the survey were: 1) 20 years of age or older, 2) a physician diagnosis of asthma or COPD, 3) regular follow-up on an outpatient basis for more than 3 months before study enrollment, and 4) agreement to participate in the survey. All participants provided written consent. Physicians filled out the questionnaire on the treatments they administered for each patient, including medications, home oxygen therapy, and pulmonary rehabilitation. Data on age, sex, body mass index (BMI), smoking status, pulmonary function test results, symptoms of asthma, the modified Medical Research Council (mMRC) scale, COPD assessment test (CAT) score, and hospitalization for exacerbation in the previous year were also collected from the medical records. Patients were divided into two groups: the elderly group aged 65 and over and the non-elderly group aged less than 65 years old.

This study was approved by the Medical Research Ethics Committee of Tokyo Medical and Dental University (approval date: October 10, 2014; Approval \#1883) and by the institutional review boards of the participating hospitals.

\subsection{Statistical Analysis}

Statistical analyses were performed using GraphPad Prism 5 software (GraphPad, California, USA). Continuous variables were summarized as means and standard deviations. Categorical data were summarized as numbers and percentages. Denominators varied according to missing responses. The Student's t-test and Chi-square test were applied for comparisons between two groups. A $P$ value of 
less than 0.05 was regarded as statistically significant.

\section{Results}

\subsection{Patient Characteristics}

Data on 3426 patients from 16 institutes were collected and the 76 respiratory physicians practicing at the institutes answered the questionnaire. Out of 2466 patients with identified asthma, 21 patients with incomplete demographic information (sex, age) and 404 ACOS patients diagnosed with both asthma and COPD were excluded. The remaining 2,041 patients were used for the study. The patients in this population had a mean age of 61.2 years. In total, 747 (36.6\%) of the patients were males, 648 (36.9\%) had a smoking history $(25.7 \pm 25.6$ packyears), 1018 (49.9\%) were 65 years old or older, and 1023 (50.1\%) were under 65 years old. Table 1 compares the patient characteristics between those aged 65 and over (elderly) and less than 65 (non-elderly). The mean ages of the elderly and non-elderly were 74.4 and 47.8 years, respectively. The elderly group had a significantly lower BMI, lower percentage of current smokers, and poorer pulmonary function than the non-elderly group.

Table 1. Patient characteristics.

\begin{tabular}{|c|c|c|c|}
\hline & $\begin{array}{c}\text { Elderly } \\
\text { ( } \geq 65 \text { years) }\end{array}$ & $\begin{array}{c}\text { Non-elderly } \\
\text { (<65 years) }\end{array}$ & $p$ \\
\hline Total number & 1018 & 1023 & \\
\hline Age, years & $74.4 \pm 9.7$ & $47.8 \pm 11.2$ & $<0.01$ \\
\hline \multicolumn{4}{|l|}{ Age group, n (\%) } \\
\hline$<45$ years & & $371(36.2)$ & \\
\hline 45 - 54 years & & $324(31.7)$ & \\
\hline $55-64$ years & & $328(32.1)$ & \\
\hline $65-74$ years & $553(54.3)$ & & \\
\hline 75 - 84 years & $384(37.7)$ & & \\
\hline$\geq 85$ years & $81(8.0)$ & & \\
\hline Male, n (\%) & $374(36.7)$ & $373(36.5)$ & 0.89 \\
\hline BMI, $\mathrm{kg} / \mathrm{m}^{2}$ & $23.4 \pm 3.8$ & $24.3 \pm 5.1$ & $<0.01$ \\
\hline Smoking status, n (\%) & & & $<0.01$ \\
\hline Known & 879 & 877 & \\
\hline Never & $569(64.7)$ & $539(61.5)$ & \\
\hline Former & $291(33.1)$ & $255(29.1)$ & \\
\hline Current & $19(2.2)$ & $83(9.5)$ & \\
\hline Smoking amount, pack-years & $34.2 \pm 30.6$ & $17.9 \pm 16.6$ & $<0.01$ \\
\hline \multicolumn{4}{|l|}{ Pulmonary function test } \\
\hline VC, \% predicted & $94.9 \pm 18.1$ & $101.6 \pm 15.6$ & $<0.01$ \\
\hline FVC, $\%$ predicted & $92.7 \pm 18.4$ & $101.6 \pm 15.6$ & $<0.01$ \\
\hline FEV1, \% predicted & $83.0 \pm 21.7$ & $89.9 \pm 19.0$ & $<0.01$ \\
\hline FEV1/FVC (\%) & $69.1 \pm 11.9$ & $75.5 \pm 11.8$ & $<0.01$ \\
\hline
\end{tabular}

Data are given as the mean \pm SD unless otherwise indicated. For smoking status, percentages were calculated based on the number of known patients. BMI, body mass index; VC, vital capacity; FVC, forced vital capacity; $\mathrm{FEV}_{1}$, forced expiratory volume in one second. 


\subsection{Details of Treatment}

In the questionnaire survey, the respiratory physicians provided details on the treatments the patients received. Figure 1 compares the medications received by the elderly and non-elderly. The treatments administered in the elderly and non-elderly patients were as follows: inhaled corticosteroids (ICS) in $96.0 \%$ and 97.0\%, long-acting beta-agonists (LABA, inhaler or transdermal patch) in $71.9 \%$ and $75.5 \%$, long-acting muscarinic antagonists (LAMA) in 3.9\% and $4.9 \%$, and leukotriene receptor antagonists (LTRA) in $46.4 \%$ and $50.3 \%$, respectively. There were no significant differences between the two groups in the prescription rates of ICS, LABA, LAMA, LTRA, theophylline, oral corticosteroids, or omalizumab. The elderly received anti-allergic drugs other than LTRA (antihistamines, Th2 cytokine inhibitors, thromboxane A2 receptor antagonists) less frequently than the non-elderly ( $8.0 \%$ vs. $10.7 \%, P=0.04)$. Mucoactive drugs, namely, mucoregulators and expectorants $(18.7 \%$ vs. $12.3 \%, P<0.01)$ and macrolides $(7.9 \%$ vs. $4.0 \%, P<0.01$ ), were prescribed significantly more frequently for the elderly than for the non-elderly. Four elderly and six non-elderly patients received traditional Japanese herbal medicine (kampo), 4 elderly patients and 1 non-elderly patient received home oxygen therapy, and 1 elderly patient underwent pulmonary rehabilitation.

\subsection{Drug Delivery Devices}

The types of preferred drug delivery devices prescribed for the elderly were also analyzed. Patients using both types of device were doubly counted. Table 2 shows the results. Among patients receiving LABA, the proportion receiving

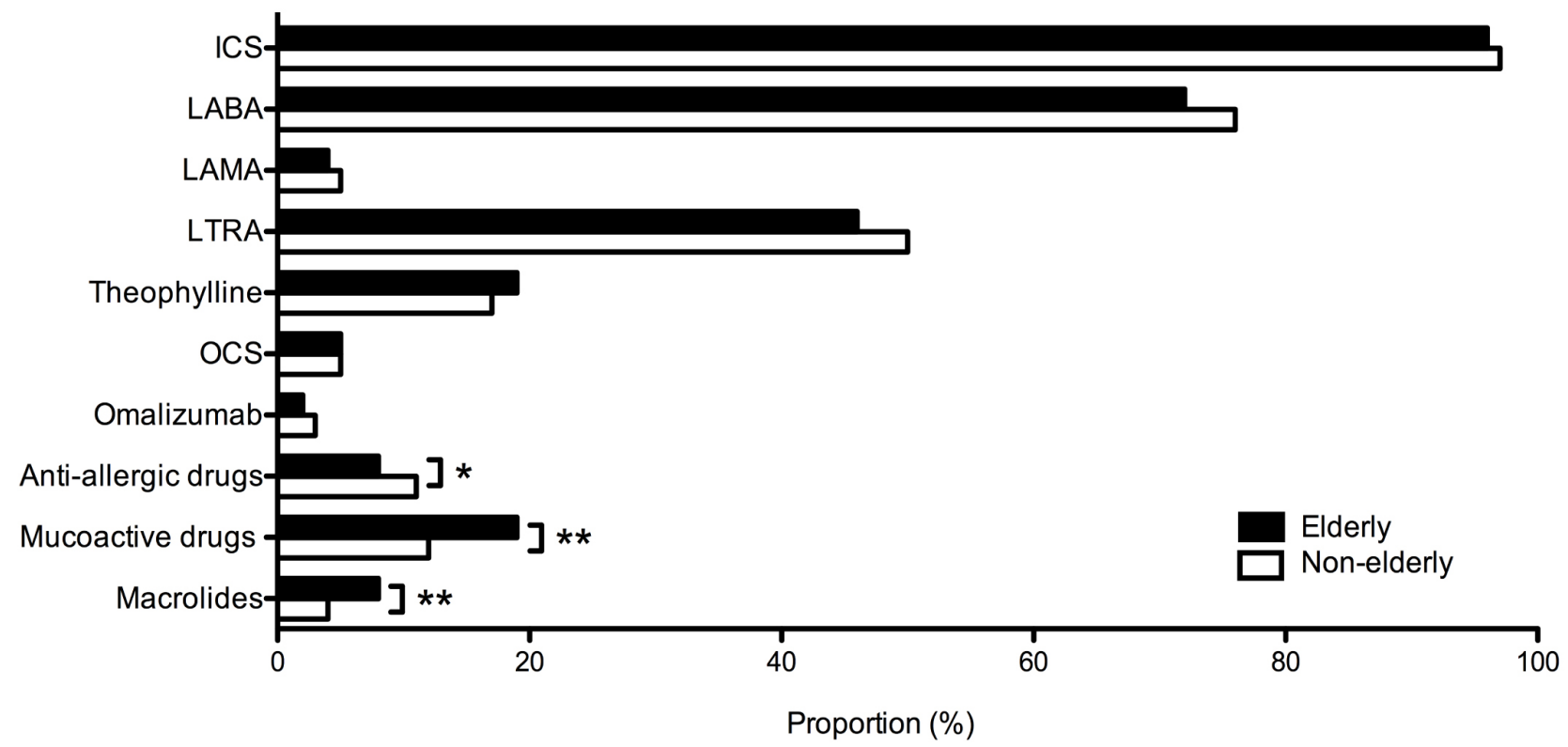

Figure 1. Treatment prescribed by respiratory physicians for elderly (black columns) and non-elderly (white columns) patients with asthma. ICS, inhaled corticosteroids; LABA, inhaled or transdermal long-acting beta-agonists; LAMA, long-acting muscarinic antagonists; LTRA, leukotriene receptor antagonists; OCS, oral corticosteroids. Mucoactive drugs include mucoregulators and expectorants. ${ }^{\star} P<0.05,{ }^{* *} P<0.01$. 
Table 2. Drug delivery devices prescribed for the elderly and the non-elderly.

\begin{tabular}{cccc}
\hline & $\begin{array}{c}\text { Elderly } \\
(\geq 65 \text { years }) \\
(\mathrm{n}=1018)\end{array}$ & $\begin{array}{c}\text { Non-elderly } \\
(<65 \text { years }) \\
(\mathrm{n}=1023)\end{array}$ & $p$ \\
\hline LABA, n (\%) & $35(4.7)$ & $19(2.4)$ & 0.02 \\
Transdermal LABA & $709(95.3)$ & $760(97.6)$ & 0.75 \\
Inhaled LABA & $147(14.9)$ & $159(15.5)$ & \\
ICS or ICS/LABA, n (\%) & $837(85.1)$ & $864(84.5)$ & \\
PMDI & & & \\
DPI & $696(96.0)$ & $745(97.4)$ & \\
ICS + LABA, n (\%) & $29(4.0)$ & $20(2.6)$ & \\
Combination & & & \\
Separation & & & \\
\hline
\end{tabular}

Patients using both types were doubly counted. LABA, long-acting beta-agonists; ICS, inhaled corticosteroids; pMDI, pressurized metered-dose inhaler; DPI, dry powder inhaler.

transdermal LABA was significantly higher in the elderly than in the non-elderly ( $4.7 \%$ vs. $2.4 \%, P=0.02)$. Among patients receiving ICS or ICS/LABA combinations, the proportion of patients using pressurized metered-dose inhalers (pMDIs) did not differ between the elderly and non-elderly (14.9\% vs. 15.5\%). Among patients receiving both ICS and LABA, the proportion of patients receiving ICS/LABA combinations did not significantly differ between the elderly and non-elderly (96.0\% vs. $97.4 \%)$.

\subsection{Asthma Symptoms and the mMRC Scale}

We analyzed the survey data on the patients' asthma symptoms and the mMRC scale. Figure 2(a) shows the existence and frequency of asthma symptoms in the elderly and non-elderly. The proportion of asymptomatic patients was significantly higher in the elderly than in the non-elderly (635/974 [65.2\%] vs 544/ 1000 [54.4\%], $P<0.01)$.

As Figure 2(b) shows, the proportion of patients scoring 0 on the mMRC scale was significantly lower in the elderly than in the non-elderly (439/704 [62.4\%] vs. $472 / 605$ [78.0\%], $P<0.01)$.

\subsection{Hospitalizations for Exacerbation in the Previous Year}

We analyzed the survey data on hospitalizations due to asthma exacerbation. The proportion of patients who had been hospitalized in the previous year did not differ between the elderly and non-elderly (54/974 [5.5\%] vs. 56/992 [5.6\%]). When we performed a further analysis disregarding age, however, a significantly higher proportion of patients receiving mucoactive drugs or macrolides had been hospitalized in the previous year compared to patients not receiving them ( $10.1 \%$ vs. $4.8 \%, P<0.01 ; 19.8 \%$ vs. $4.8 \%, P<0.01$; respectively). 


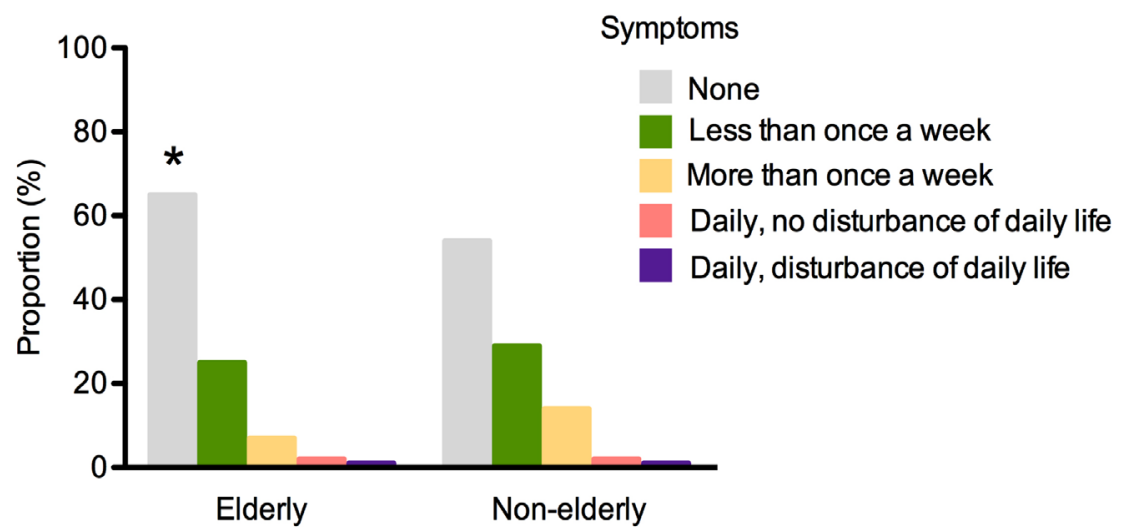

(a)

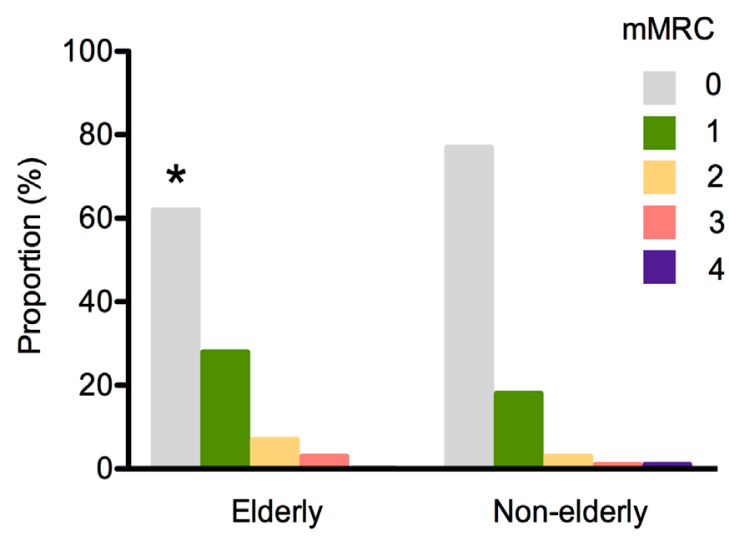

(b)

Figure 2. (a) The frequency of asthma symptoms. The respective columns show the proportions of patients with no symptoms (gray), symptoms less than once a week (green), symptoms more than once a week (yellow), daily symptoms with no disturbance of daily life (red), daily symptoms with disturbance of daily life (purple); $\mathrm{n}=974$ in the elderly, $\mathrm{n}=$ 1000 in the non-elderly. (b) The modified Medical Research Council (mMRC) scale. The respective columns show the proportions of patients with $\mathrm{mMRC}$ scale 0 (gray), 1 (green), 2 (yellow), 3 (red), and 4 (purple); $\mathrm{n}=704$ in the elderly, $\mathrm{n}=605$ in the non-elderly. ${ }^{\star} P<0.01$ compared to the non-elderly.

\section{Discussion}

According to the questionnaire survey on treatments administered to adult patients with asthma in Japan, the prescription rates of mucoactive drugs, macrolides, and transdermal LABA were significantly higher in the elderly than in the non-elderly. There were no significant differences in the prescription rates of ICS, LABA (inhaler or transdermal patch), LAMA, or LTRA between the same two groups.

Although asthma in the elderly has been commonly recognized as undertreated [7], one recent study has shown that the elderly are often prescribed ICS and receive relatively aggressive care compared to younger patients [18]. Similarly, the present study found no significant differences between the elderly and non-elderly in the prescription rates of major controller medications such as ICS, LABA, LAMA, or LTRA. Neither the Global Initiative for Asthma (GINA) 
2016 nor the guideline from the Japanese Society of Allergology in 2015 makes any recommendations on the use of mucoactive drugs or macrolides for asthmatic patients [14] [19]. Some of the patients in this study, however, received these medications in clinical settings in Japan. The proportion of patients who had been hospitalized in the previous year was significantly higher among the patients receiving mucoactive drugs or macrolides than among those not receiving them. We assumed, therefore, that the respiratory physicians in our study considered these medications as treatment options for asthma. Indeed, a real-world investigation in Italy recently reported that macrolides influenced the reduction of severe asthma exacerbations [20]. Several clinical trials and animal experiments have demonstrated that mucoactive drugs can prevent airway hyperresponsiveness [21] [22] [23]. Another possible reason for the higher prescription rates of mucoactive drugs or macrolides for the elderly in our study was the convenience of administering these medications regardless of low inspiratory flow rates or poor inhaler technique.

On the question of drug delivery, previous studies reported that transdermal LABA was effective in improving asthma control and health status [24] [25], and that elderly patients adhere to transdermal LABA more faithfully than to inhaled LABA [26]. The physicians surveyed in our study prescribed transdermal LABA more frequently for the elderly than for the non-elderly, possibly because they recognized these benefits.

Underreporting of subjective symptoms is considered an important issue in elderly asthmatics, given the portended risk of treatment delay [27]. The elderly have been shown to be less aware of their own symptoms of bronchoconstriction [28]. Similarly, our study identified a significantly higher proportion of asymptomatic patients among the elderly. Several possible explanations for this finding are available: the elderly might be less aware of their symptoms or less likely to report them; physicians might be less reliable in recognizing asthma symptoms in the elderly; asthma in the elderly might actually be well controlled. In either case, physicians should carefully monitor their patients and use objective measures of asthma control, especially for asthma in the elderly.

Dyspnea, a common symptom in the elderly, is mainly caused by respiratory disease, cardiovascular disease, deconditioning, and respiratory muscle weakness [29]. While the proportion of patients complaining of dyspnea in our study was significantly higher in the elderly than in the non-elderly, we could not tell whether any comorbidities were affecting their symptoms. Further surveys will be required to accurately identify the causes of their dyspnea.

Hospitalizations for asthma are reported to be more common in older adults than in younger adults [27] [30]. On the contrary, there was no significant difference in the proportion of hospitalizations due to asthma exacerbation between the elderly and non-elderly in our study. This might be explained by the exclusion of ACOS patients, a population significantly older and at greater risk of hospitalizations than patients with asthma alone [31] [32], from our analysis. When we included 404 patients with ACOS in the analysis, the proportion of 
hospitalizations in the previous year became significantly higher in the elderly than in the non-elderly ( $8.0 \%$ vs. $5.7 \%, P=0.03)$.

Our study was subject to two important limitations. First, we used cross-sectional data for the analyses. Second, the questionnaire targeted not patients, but physicians, who may have had an incomplete understanding of the patients' subjective symptoms or their adherence to the treatments prescribed. We assume that our study was meaningful in spite of these limitations, as it was conducted on a large population of elderly patients and faithfully reflected their management in real-world clinical settings at multiple institutions.

In conclusion, mucoactive drugs, macrolides, and transdermal LABA were more likely to be prescribed for the elderly asthmatic patients than for the non-elderly asthmatics, whereas the prescription rates of major controller medications such as ICS, LABA (inhaler or transdermal patch), LAMA, or LTRA did not differ by age.

\section{References}

[1] Oraka, E., Kim, H.J., King, M.E. and Callahan, D.B. (2012) Asthma Prevalence among US Elderly by Age Groups: Age Still Matters. Journal of Asthma, 49, 593 599. https://doi.org/10.3109/02770903.2012.684252

[2] Arif, A.A., Rohrer, J.E. and Delclos, G.L. (2005) A Population-Based Study of Asthma, Quality of Life, and Occupation among Elderly Hispanic and Non-Hispanic Whites: A Cross-Sectional Investigation. BMC Public Health, 5, 97.

https://doi.org/10.1186/1471-2458-5-97

[3] Nejjari, C., Tessier, J.F., Letenneur, L., Dartigues, J.F., Barberger-Gateau, P. and Salamon, R. (1996) Prevalence of Self-Reported Asthma Symptoms in a French Elderly Sample. Respiratory Medicine, 90, 401-408. https://doi.org/10.1016/S0954-6111(96)90113-4

[4] Yáñez, A., Cho, S.H., Soriano, J.B., Rosenwasser, L.J., Rodrigo, G.J., Rabe, K.F., Peters, S., Niimi, A., Ledford, D.K., Katial, R., Fabbri, L.M., Celedón, J.C., Canonica, G.W., Busse, P., Boulet, L.P., Baena-Cagnani, C.E., Hamid, Q., Bachert, C., Pawankar, R. and Holgate, S.T. (2014) Asthma in the Elderly: What We Know and What We Have Yet To Know. World Allergy Organization Journal, 7, 8. https://doi.org/10.1186/1939-4551-7-8

[5] Moorman, J.E. and Mannino, D.M. (2001) Increasing U.S. Asthma Mortality Rates: Who Is Really Dying? Journal of Asthma, 38, 65-71. https://doi.org/10.1081/JAS-100000023

[6] Plaza, V., Serra-Batlles, J., Ferrer, M. and Morejón, E. (2000) Quality of Life and Economic Features in Elderly Asthmatics. Respiration, 67, 65-70. https://doi.org/10.1159/000029465

[7] Enright, P.L., McClelland, R.L., Newman, A.B., Gottlieb, D.J. and Lebowitz, M.D. (1999) Underdiagnosis and Undertreatment of Asthma in the Elderly. Chest, 116, 603-613.

[8] Janssens, J.P., Pache, J.C. and Nicod, L.P. (1999) Physiological Changes in Respiratory Function Associated with Ageing. European Respiratory Journal, 13, 197-205.

[9] Lowery, E.M., Brubaker, A.L., Kuhlmann, E. and Kovacs, E.J. (2013) The Aging Lung. Clinical Interventions in Aging, 8, 1489-1496.

[10] Barnett, K., Mercer, S.W., Norbury, M., Watt, G., Wyke, S. and Guthrie, B. (2012) 
Epidemiology of Multimorbidity and Implications for Health Care, Research, and Medical Education: A Cross-Sectional Study. The Lancet, 380, 37-43. https://doi.org/10.1016/S0140-6736(12)60240-2

[11] Gibson, P.G. and Simpson, J.L. (2009) The Overlap Syndrome of Asthma and COPD: What Are Its Features and How Important Is It? Thorax, 64, 728-735. https://doi.org/10.1136/thx.2008.108027

[12] Kowal, P., Goodkind, D. and He, W. (2016) An Aging World: 2015, International Population Reports. U.S. Government Printing Office, Washington DC. http://www.census.gov/library/publications/2016/demo/P95-16-1.html

[13] Portal Site of Official Statistics of Japan (e-Stat). Patient Survey. http://www.e-stat.go.jp/SG1/estat/eStatTopPortal.do

[14] Japanese Society of Allergology, Asthma Guideline Committee (2015) Asthma Prevention and Management Guidelines 2015. Kyowa Kikaku, Tokyo.

[15] Boulet, L.P. (2016) Asthma in the Elderly Patient. Asthma Research and Practice, 2, 3. https://doi.org/10.1186/s40733-015-0015-1

[16] Melani, A.S. (2013) Management of Asthma in the Elderly Patient. Clinical Interventions in Aging, 8, 913-922. https://doi.org/10.2147/CIA.S33609

[17] Battaglia, S., Benfante, A., Spatafora, M. and Scichilone, N. (2016) Asthma in the Elderly: A Different Disease? Breathe, 12, 18-28.

https://doi.org/10.1183/20734735.002816

[18] Slavin, R.G., Haselkorn, T., Lee, J.H., Zheng, B., Deniz, Y. and Wenzel, S.E., TENOR Study Group (2006) Asthma in Older Adults: Observations from the Epidemiology and Natural History of Asthma: Outcomes and Treatment Regimens (TENOR) Study. Annals of Allergy, Asthma \& Immunology, 96, 406-414. https://doi.org/10.1016/S1081-1206(10)60907-6

[19] Global Initiative for Asthma (GINA) (2016) Global Strategy for Asthma Management and Prevention 2016. ginaasthma.org

[20] Arfè, A., Blasi, F., Merlino, L. and Corrao, G. (2016) Respiratory Drugs and Macrolides Prevent Asthma Exacerbations: A Real-World Investigation. Respiratory Medicine, 119, 7-12. https://doi.org/10.1016/j.rmed.2016.05.004

[21] Takeda, K., Miyahara, N., Matsubara, S., Taube, C., Kitamura, K., Hirano, A., Tanimoto, M. and Gelfand, E.W. (2016) Immunomodulatory Effects of Ambroxol on Airway Hyperresponsiveness and Inflammation. Immune Network, 16, 165-175. https://doi.org/10.4110/in.2016.16.3.165

[22] Ueno-Iio, T., Shibakura, M., Iio, K., Tanimoto, Y., Kanehiro, A., Tanimoto, M. and Kataoka, M. (2013) Effect of Fudosteine, a Cysteine Derivative, on Airway Hyperresponsiveness, Inflammation, and Remodeling in a Murine Model of Asthma. Life Sciences, 92, 1015-1023.

[23] Ishiura, Y., Fujimura, M., Yamamori, C., Nobata, K., Myou, S., Kurashima, K., Michishita, Y. and Takegoshi, T. (2003) Effect of Carbocysteine on Cough Reflex to Capsaicin in Asthmatic Patients. British Journal of Clinical Pharmacology, 55, 504510. https://doi.org/10.1046/j.1365-2125.2003.01788.x

[24] Nishiyama, O., Taniguchi, H., Kondoh, Y., Kimura, T., Kato, K., Kume, H. and Shimokata, K. (2006) Comparison of the Effects of Tulobuterol Patch and Salmeterol in Moderate to Severe Asthma. Clinical and Experimental Pharmacology and Physiology, 33, 1016-1021. https://doi.org/10.1111/j.1440-1681.2006.04480.x

[25] Inoue, H., Niimi, A., Matsumoto, H., Ito, I., Oguma, T., Otsuka, K., Takeda, T., Nakaji, H., Tajiri, T., Iwata, T., Nagasaki, T. and Mishima, M. (2017) A 12-Week, Randomized, Parallel-Group, Proof-of-Concept Study of Tulobuterol Patch and 
Salmeterol Inhaler as Add-On Therapy in Adult-Onset Mild-to-Moderate Asthma. Clinical and Experimental Pharmacology and Physiology, 44, 21-29. https://doi.org/10.1111/1440-1681.12683

[26] Mochizuki, H., Nanjo, Y. and Takahashi, H. (2013) Better Adherence to a Transdermal Tulobuterol Patch than Inhaled Salmeterol in Elderly Chronic Obstructive Pulmonary Disease Patients. Geriatrics \& Gerontology International, 13, 398-404. https://doi.org/10.1111/j.1447-0594.2012.00916.x

[27] Hanania, N.A., King, M.J., Braman, S.S., Saltoun, C., Wise, R.A., Enright, P., Falsey, A.R., Mathur, S.K., Ramsdell, J.W., Rogers, L., Stempel, D.A., Lima, J.J., Fish, J.E., Wilson, S.R., Boyd, C., Patel, K.V., Irvin, C.G., Yawn, B.P., Halm, E.A., Wasserman, S.I., Sands, M.F., Ershler, W.B. and Ledford, D.K., Asthma in Elderly Workshop Participants (2011) Asthma in the Elderly: Current Understanding and Future Research Needs-A Report of a National Institute on Aging (NIA) Workshop. The Journal of Allergy and Clinical Immunology, 128, S4-S24.

https://doi.org/10.1016/j.jaci.2011.06.048

[28] Connolly, M.J., Crowley, J.J., Charan, N.B., Nielson, C.P. and Vestal, R.E. (1992) Reduced Subjective Awareness of Bronchoconstriction Provoked by Methacholine in Elderly Asthmatic and Normal Subjects as Measured on a Simple Awareness Scale. Thorax, 47, 410-413. https://doi.org/10.1136/thx.47.6.410

[29] Silvestri, G.A. and Mahler, D.A. (1993) Evaluation of Dyspnea in the Elderly Patient. Clinics in Chest Medicine, 14, 393-404.

[30] Tsai, C.L., Delclos, G.L., Huang, J.S., Hanania, N.A. and Camargo Jr., C.A. (2013) Age-Related Differences in Asthma Outcomes in the United States, 1988-2006. Annals of Allergy, Asthma \& Immunology, 110, 240-246. https://doi.org/10.1016/j.anai.2013.01.002

[31] Menezes, A.M., Montes de Oca, M., Pérez-Padilla, R., Nadeau, G., Wehrmeister, F.C., Lopez-Varela, M.V., Muiño, A., Jardim, J.R., Valdivia, G. and Tálamo, C., PLATINO Team (2014) Increased Risk of Exacerbation and Hospitalization in Subjects with an Overlap Phenotype: COPD-Asthma. Chest, 145, 297-304.

[32] Nielsen, M., Bårnes, C.B. and Ulrik, C.S. (2015) Clinical Characteristics of the Asthma-COPD Overlap Syndrome-A Systematic Review. International Journal of Chronic Obstructive Pulmonary Disease, 10, 1443-1454. 


\section{Appendix: Survey Questionnaire}

Date: //

$\square$ Asthma $\square$ Previously diagnosed asthma (in remission) $\square$ COPD

Age:

Sex: Male/Female

Smoking status: Current/Ex/Never/Unknown,

cigarettes per day $\times$ years

BMI:

GOLD classification of severity of airflow limitation in COPD: $\square$ I $\square$ II $\square$ III $\square$ IV $\square$ Unknown

Symptoms of asthma:

$\square$ Absence

$\square$ Presence: Less than once a week/More than once a week/

Daily, no disturbance of daily life/Daily, disturbance of daily life

$\square$ Unknown

mMRC: $\square 0 \square 1 \square 2 \square 3 \square 4 \square$ Unknown

CAT: $\square$ Unknown

Pulmonary function test:

\begin{tabular}{|c|c|c|c|}
\hline$\% \mathrm{VC}$ & $\%$ & $\%$ DLCO & $\%$ \\
\hline$\% \mathrm{FVC}$ & $\%$ & $\% \mathrm{DLCO} / \mathrm{VA}$ & $\%$ \\
\hline$\%$ FEV 1 & _ $\%$ & RV/TLC (\%) & \% \\
\hline
\end{tabular}

FEV1/FVC (\%) _ $\%$

Treatment:

$\square$ ICS:

$\square$ LABA:

$\square$ ICS/LABA:

$\square$ LAM A:

$\square$ LABA/LAM A:

$\square$ SABA $\square$ SAM A

$\square$ LTRA $\square$ Theophylline

$\square$ Traditional Japanese herbal medicine (kampo)

$\square$ Omalizumab $\square$ Oral corticosteroids

$\square$ Macrolides $\square$ Mucoactive drugs

$\square$ Anti-allergic drugs

$\square$ Home oxygen therapy

$\square$ Pulmonary rehabilitation

COPD exacerbation in the previous year:

Hospitalization for COPD exacerbation in the previous year:

Hospitalization for asthma exacerbation in the previous year: 
Submit or recommend next manuscript to SCIRP and we will provide best service for you:

Accepting pre-submission inquiries through Email, Facebook, LinkedIn, Twitter, etc. A wide selection of journals (inclusive of 9 subjects, more than 200 journals)

Providing 24-hour high-quality service

User-friendly online submission system

Fair and swift peer-review system

Efficient typesetting and proofreading procedure

Display of the result of downloads and visits, as well as the number of cited articles Maximum dissemination of your research work

Submit your manuscript at: http://papersubmission.scirp.org/

Or contact ijcm@scirp.org 